major chunk of women's contributions to the Indian Journal of Psychiatry. Reviews, invited articles, presidential addresses, editorials, commentaries, orations and critiques by women authors in the journal are negligible.

No woman psychiatrist acts as advisor to the Government of India on policy matters related to mental health in general or in relation to women. ${ }^{3}$

As far as looking after the specific needs related to their family-related roles, there are no guidelines for pregnancy and maternity leave for women postgraduate students in the country. If a woman joins a government job, there is a provision for maternity leave, but this often is not available for postgraduate students. Few hospitals or medical colleges provide reliable on-site day care and school-based childcare is not available when children are older. On discontinuation of a job for family building or other reasons, options for career revival after a certain period are presently unavailable because of age restrictions.

There is no association of women psychiatrists at regional or national level. ${ }^{2}$ Unlike high-income countries, where specific needs, aspirations, areas of interest, monetary incentives, working styles, characteristics and other issues related to women psychiatrists have been studied and attempts have been made to address these, there is negligible research in this area in low-income countries. Moreover, women have a negligible role in policy-making in psychiatry.

Currently, there is no system addressing the specific issues related to women doctors as a whole in India and other neighbouring countries on the Indian subcontinent. ${ }^{2}$

1 Dutta R, Hawkes SL, Iversen AC, Howard L. Women in academic psychiatry. Psychiatrist 2010; 34: 313-7.

2 Sood M, Chadda RK. Women in psychiatry: a view from the Indian subcontinent. Indian J Psychiatry 2009; 51: 199-201.

3 Sood M, Chadda RK. Women psychiatrists in India: a reflection of their contributions. Indian J Psychiatry 2010; 52: 396-401.

Mamta Sood Psychiatrist, All India Institute of Medical Sciences, New Delhi, India, email: soodmamta@gmail.com, Rakesh K. Chadda, Professor of Psychiatry, All India Institute of Medical Sciences, New Delhi.

doi: 10.1192/pb.34.11.498a

\section{Is the assessed capacity increased with the seriousness of what is at stake?}

In $\operatorname{Re} T^{1,2}$ the Court of Appeal had to consider the case of an adult Jehovah's Witness who refused treatment. A pregnant woman was involved in a car accident and, after speaking with her mother, signed a form of refusal of blood transfusion. After the delivery of a stillborn baby, her condition deteriorated, therefore a Court order was obtained in order to legalise a blood transfusion on the grounds that it was in the woman's best interest. In this case the Court of Appeal addressed the question related to capacity, life-threatening situation and right to refuse a medical treatment, particularly in relation to the degree of risk involved in a particular decision: 'What matters is that the doctor should consider whether at that time he had a capacity which was commensurate with the gravity of the decision. The more serious the decision, the greater the capacity required.' It is interesting to consider, as pointed out by Buchanan, 'What principles then govern the practice, described in $\operatorname{Re} T$, whereby the level of capacity required for competence rises in proportion to what is at stake?' In other terms, is the assessed capacity required for legal competence increased with the seriousness of what is at stake? Perhaps the assessment of capacity has to consider the importance, the risk and the gravity of the decision that the patient has to make. Following this train of thought, maybe different standards of competence are needed in order to ensure that genuine choices are being made.

Buchanan \& Brock $^{4}$ were more inclined to sustain this view in terms of capacity, whereas Culvert \& Gert ${ }^{5}$ and Wicclair ${ }^{6}$ found the idea of different standards of competence more paternalistic-oriented. Culvert $\&$ Gert argued that the capacity related to the degree of risk was against the principle of 'symmetrical competence' and pointed out that the change of external risk can potentially change the status of a person from competent to incompetent, 'a fact inconsistent with the idea that competence is a genuine attribute of a person'.

$1 \operatorname{Re} T$ (adult) (refusal of medical treatment) [1992] 4All ER 649, (1992) 9 BMLR 46, CA.

$2 \operatorname{Re} T$ (adult) (refusal of medical treatment) [1992] 4 All ER 649.

3 Buchanan A. Mental capacity, legal competence and consent to treatment. J R Soc Med 2004; 97: 415-20.

4 Buchanan AE, Brock DW. Deciding for Others: The Ethics of Surrogate Decision Making. Cambridge University Press, 1989.

5 Culver C, Gert B. The inadequacy of incompetence. Milbank Q 1990; 68 619-43.

6 Wicclair M. Patient decision-making capacity and risk. Bioethics 1991; 5: 91-104.

Margherita Tanzarella Specialty Doctor, Surrey and Border Partnership NHS Foundation Trust, email: TMargherita@sabp.nhs.uk, Salvatore Marco Mura Specialist Trainee Registrar Year 3, South West London and St George's Mental Health NHS Trust.

doi: $10.1192 / p b .34 .11 .499$

\section{Inconsistencies in Section 136 assessments}

Liz Tate ${ }^{1}$ rightfully mentioned that there are junior trainees attending to the Section 136 assessments, despite clear guidance in the Mental Health Act Code of Practice that it should be done by Section 12(2)-approved doctors. Further to that, the Code states that a reason should be documented for divulging from the aforementioned practice. In most places this practice of assessments by a non-Section 12(2)-approved doctor is a protocol and a norm.

Every directorate and trust has its own local policies, keeping the Code of Practice as standard. For the formulation of a local policy, representatives from multiple agencies such as police, accident and emergency departments, ambulance services, Social Services and mental health services formulate guidelines for the fluidity of the process of Section 136 assessments. Timescales are set for the completion of these assessments and are regularly reviewed.

There are provisions for middle tier or consultant cover to facilitate the Section 136 assessments. Despite these arrangements, there are units where the attendance of nonSection 12(2)-approved doctors is the first port of call for such assessment; after a detailed history has been taken from the patient, the Section 12(2)-approved doctor is contacted and the assessment completed. Furthermore, it is known that there are places where non-Section 12(2)-approved doctors discharge patients after having discussions over the telephone with a Section 12(2)-approved doctor. It has also been found 
that there are times when patients are admitted to in-patient beds under Section 136 for more than 48 hours, for example because the concerned Section 12(2)-approved doctor is reluctant to come out to complete the Section 136 assessment out of hours. There are few places where the Code of Practice is scrupulously followed and Section 12(2)-approved doctors are the first port of contact.

It makes you wonder that despite being a part of the legal system, Section 136 is very poorly managed as compared with the other sections of the Mental Health Act. There is no unitary form for Section 136 assessment documentation and no accountability for the assessments and detention of persons on Section 136. The time is right to make amends for this varied practice and for measures to be taken to get it right.

1 Tate L. Inexperienced trainees doing more Section 136 assessments (e-letter). Psychiatrist 2010; 26 July (http://pb.rcpsych.org/cgi/eletters/ 34/7/268\#10147)

Khurram Sadiq Locum Consultant Psychiatrist, Greater Manchester West Mental Health NHS Foundation Trust, email: khurramlodhi74@hotmail.com, Rupali Acharya, CT2 Psychiatry, Trafford.

doi: 10.1192/pb.34.11.499a

\section{Can making physical healthcare policies more readable improve healthcare standards?}

Gonzalez et al have pointed out an interesting omission in the form of poor physical healthcare monitoring in routine psychiatric practice and there is evidence from various local and national audits ${ }^{2,3}$ that it is not restricted to just the outpatient settings. The authors have also rightly picked up on key barriers to the implementation of physical healthcare monitoring in psychiatric settings, namely unclear responsibilities, competing demands on limited resources and liability issues. We believe that, for a start, this can be addressed by having readable, succinct and unambiguous physical healthcare policies.

Tosh et $a l^{4}$ examined the physical healthcare policy documents of the three mental healthcare trusts in the north sector of the East Midlands Strategic Healthcare Authority in detail. We found significant disparities between the policies in terms of size, readability, external references and reading cost. All the policies incorporated vague language in their directives and none could be read swiftly. It is only fair to make a reasonable observation here that if a policy cannot be accessed or is unfocused or vague, then it will be ignored.

Multiple layers of guidance and variation between deaneries, trusts and teams also complicate the situation. This leads to confusion and lack of confidence between team members as to which policy to follow. The result is a huge wastage of money from duplication and undermining of the ability of the policy to deliver its objectives.

A collaborative effort at the national level could produce a simple, clear and succinct policy for physical healthcare of people with serious mental illness. We believe that the Royal
College of Psychiatrists is in a unique position to take a lead on this very important aspect of patient health and well-being. There are already themes emerging from research that it is an area which is very important to the patients, carers and their families alike. ${ }^{5}$ A clear national policy statement from the College should dispel current confusion, policy fatigue and waste.

1 Gonzalez C, Ahammed N, Fisher R. Improving physical health monitoring for out-patients on antipsychotic medication. Psychiatrist 2010; 34: 91-4.

2 Abbasi Y. Improving physical health monitoring in psychiatry - change we need? Psychiatrist 2010; 34: 210-1.

3 Barnes TR, Paton C, Cavanagh MR, Hancock E, Taylor DM. A UK audit of screening for the metabolic side effects of antipsychotics in community patients. Schizophr Bull 2007; 33: 1397-403.

4 Tosh G, Clifton A, Adams CE. Physical health care policies in mental health trusts in the North East Midlands (UK). Mental Health Rev J 2010; 15: $15-20$.

5 McCrae J. Physical health concerns of the patient, the family and the carers. Eur Psychiatry 2010; 25 (suppl 2): 34-6.

Waqqas A. Khokhar Specialty Registrar, Radbourn Unit, Royal Derby Hospital, Derby, email: waqqaskhokhar@doctors.org.uk, Graeme Tosh Specialty Registrar, Nottinghamshire Healthcare NHS Trust, and Andrew Clifton Research Fellow, Institute of Mental Health, University of Nottingham.

doi: $10.1192 /$ pb.34.11.500

\section{A fishy business}

Has anyone else noticed that the epigram at the start of this paper ${ }^{1}$ is incorrectly attributed? It does not express a Taoist idea, and is not the kind of thing Lao Tsu would have written. Unfortunately, I have not been able to locate the original source. For example, it does not appear in the Oxford Dictionary of Quotations (where 20 reliable quotes from Lao Tsu are listed). At least one website also wrongly lists Lao Tsu as the author, and another refers to the quotation as a Chinese proverb, but a third calls it an English proverb. (I have been wondering if the original author might actually have been contemporary, an Oxfam official for instance.) I have checked again through Lao Tsu's Tao Te Ching, the only work of his that survives. 'Give a man a fish ... ' definitely does not appear. Indeed, the only (sole) reference to fish comes in Chapter 60: 'Governing a large country is like frying a small fish; you spoil it if you poke it around too much'. It occurs to me that a number of politicians, including particularly the Secretary of State for Health, might wisely take note of that point. What are the chances of them taking the bait?

1 Hill L, Roberts G, Igbrude W. Experience of support time and recovery workers in promoting WRAP. Psychiatrist 2010; 34: 279-84.

Larry Culliford author (retired psychiatrist), the Royal College of Psychiatrists, West Sussex, email: auud26@dsl.pipex.com

doi: 10.1192/pb.34.11.500a 